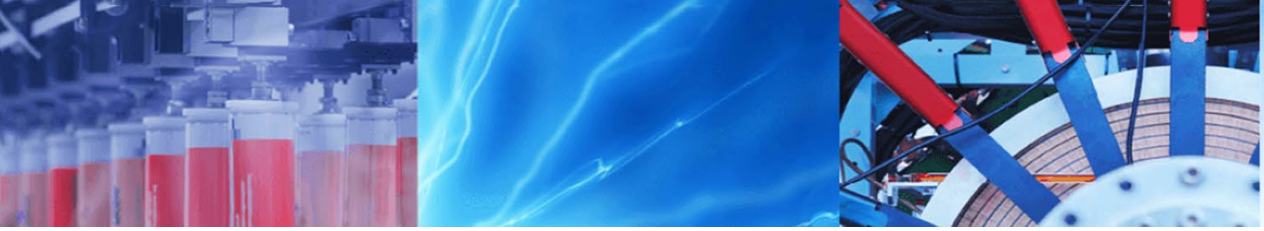

Research Article

\title{
In-situ synthesis and characterization of silver nanoparticle decorated cotton knitted fabric for antibacterial activity and improved dyeing performance
}

\author{
Imana Shahrin Tania ${ }^{1,2} \cdot{\text { Mohammad } \mathrm{Ali}^{2} \cdot \text { Md. Shafiul Azam }}^{3}$
}

() Springer Nature Switzerland AG 2018

\begin{abstract}
This study reports the antimicrobial activity and improved dyeing performance of cotton knitted fabric by depositing silver nanoparticles on the surface. The cotton fabric is first treated with caustic soda $(\mathrm{NaOH})$ of three different concentrations to activate the hydroxyl groups on the cellulose surface and then the nanoparticles are introduced on fabric surface by direct reduction of silver nitrate salt using ascorbic acid. The presence of silver nanoparticles on the fabric surface is clearly observed by scanning electron micrograph. The elementary analysis is done by energy dispersive spectroscopy and the chemical interaction of cotton fibre with nano silver is characterized by Fourier transform infrared spectrum. In this work, the antimicrobial activity on Ag deposited sample is investigated by quantitative analysis against both Gram positive (S. aureus) and Gram negative (E. coli) bacteria. Results shows a significant antimicrobial activity such as more than $90 \%$ bacterial reduction of both Gram positive and Gram negative bacteria are inhibited. The fabric sample is dyed with $2 \%$ direct dye and consequently the result shows very good performance in dye exhaustion, colour strength and fastness property. For instance, the incorporation of Ag nanoparticles increases $7 \%$ of dyestuff exhaustion and $15 \%$ of colour strength of the fabric. However, Ag nanoparticles deposited fabric loses its strength slightly due to the pretreatment using $\mathrm{NaOH}$ for the functionalization of cotton.
\end{abstract}

Keywords Cotton fabric $\cdot$ Silver $\cdot$ Nano particle $\cdot$ Antimicrobial activity $\cdot$ Dyeing performance $\cdot$ Mechanical strength

\section{Introduction}

Textile industries are important to consumer for clothing, households goods, furnishing and other textiles product. Now a days textile cloth with various functional properties is very popular. Antimicrobial textile is one of them because of the health concern of the consumer. It has become important due to an opportunity for production of protective, decorative and safe textile products. This also creates a new possibility for textile goods to be used in pharmaceutical, medical, engineering, agricultural, and food industries [1]. Antimicrobial textile is mainly obtained by finishing process of textile goods on various ways [2-6].

However cotton fabric provides an excellent environment for microorganism to grow [7]. That means it is susceptible to bacterial attack as they provide large surface area to absorb moisture required for bacterial growth. This often leads objectionable odor, dermal infection, product deterioration allergic responses and other related issues. It is therefore important to impart antimicrobial activity on cotton so as to protect the health of the wearer [8]. Some examples are inorganic salt, organometallic iodophors, phenols and triphenols,

$\triangle$ Imana Shahrin Tania, imanat008@gmail.com ; imana.butex@gmail.com| ${ }^{1}$ Department of Wet Process Engineering, Bangladesh University of Textiles (BUTEX), Tejgaon, Dhaka, Bangladesh. ${ }^{2}$ Department of Mechanical Engineering, Bangladesh University of Engineering and Technology (BUET), Dhaka 1000, Bangladesh. ${ }^{3}$ Department of Chemistry, Bangladesh University of Engineering and Technology (BUET), Dhaka 1000, Bangladesh.

SN Applied Sciences (2019) 1:64 | https://doi.org/10.1007/s42452-018-0068-x 
ammonium salts, antibiotics, nitro compounds, urea and related compounds, formaldehyde derivatives, amines etc. Most of those chemical are toxic or non biodegradable, so it is highly concerning to the environment [9]. For this reason textile industry always search for safe chemical and eco friendly process for imparting antimicrobial property. Moreover an effective antimicrobial finish should be able to kill or stop the growth of microorganisms. It has to be durable to wash or dry cleaning, compatible with other ingredients in the finishing formulation, has minimal impacts on both the environment and the product quality, and has easy to apply for low cost and low toxicity criteria [10].

The antimicrobial activity of silver is very well known and widely used as a substitute of harmful antimicrobial agent. Silver has been used in many applications in free metal or compound forms because it possesses antimicrobial activity against pathogens but is nontoxic to human body. The silver ions are very reactive leading to inhibition of microbial respiration and metabolism as well as physical damage [9]. Silver nanoparticles due to their strong and wide spectrum of antimicrobial activities have gained major focus among all nanoparticles. As bactericides, the silver nanoparticles may help in solving the serious antibiotic resistance problem [11]. It can inhibit the growth of a wide variety of micro-organisms including fungi, viruses, and bacteria. Nano Ag is very reactive with proteins, and when it comes into contact with the bacteria or fungi it inhibits cell growth. The antimicrobial activity of silver nanoparticle is related to its shape and particle size. The smaller size particle gives better performance of antimicrobial activity [12-15].

At present time nano $\mathrm{Ag}$ have been synthesized by physical milling, chemical reduction, plant leaf extraction, and solgel process $[16,17]$. Some researchers also follow the in situ route for direct synthesis of silver nanoparticle on the treated material surface [18-23]. The main problem of synthesis and application of nanoparticles are an aggregation process, causing the loss of their unique properties [24]. So in situ process is better for nanoparticle growth directly on fabric surface, there is very little chance of aggregation, where cotton fiber itself can act as a template to stabilize and control the growth of silver nanoparticles. Furthermore it offers long lasting effect and excellent wash durability of nano silver [21]. In this research very small size around $14.1 \mathrm{~nm}$ nano $\mathrm{Ag}$ is formed by in situ method and the distribution is uniform. Here caustic soda treated cotton fabric acts as a good media for the growth of Ag nanoparticles. Along with this the silver nanoparticle is regarded as a mordant for dyestuff, as a result it increases the dye affinity and consequently dye exhaustion.

\section{Experiments}

\subsection{Specification of fabric}

For the work $100 \%$ cotton knitted fabric of following construction and specification are used mentioned in Table 1.

\subsection{Chemicals}

Silver nitrate $\left(\mathrm{AgNO}_{3}, 99.9 \%\right.$ pure), sodium hydroxide pallets $\left(\mathrm{NaOH}, 99.8 \%\right.$ pure), ascorbic acid $\left(\mathrm{C}_{6} \mathrm{H}_{8} \mathrm{O}_{6}\right.$, extra pure), acetic acid $\left(\mathrm{CH}_{3} \mathrm{COOH}\right)$ are purchased from Merck, Germany. For dying C.I. Direct red 9, leveling agent and glauber salt $\left(\mathrm{Na}_{2} \mathrm{SO}_{4} \cdot 10 \mathrm{H}_{2} \mathrm{O}\right)$ are collected from Meghmani Dyes and intermediates Ltd, India. All experiments are performed at room temperature.

\subsection{Methods}

\subsubsection{Synthesis of silver nanoparticles}

Scoured and bleached cotton fabric is impregnated on different concentration of caustic soda solution $(1 \mathrm{M}, 2 \mathrm{M}$, $3 \mathrm{M}$ ) with $1: 30 \mathrm{~mL}$ ratio and kept $5 \mathrm{~min}$, then alkali pretreated cotton fabric is kept on $\mathrm{AgNO}_{3}$ solution of $1 \mathrm{M}$ concentration at room temperature. One sample is immersed in same concentration of silver nitrate solution without treating with caustic soda. This is denoted by Sk-1 (Silver knit-1). Then fabric is penetrated on $0.01 \mathrm{M}$ ascorbic acid and stay at $30 \mathrm{~min}$. Here ascorbic acid has the ability to precipitate the metallic silver in acid solution. The treated samples are denoted as Sk-1 for without caustic treated, Sk-2 for $1 \mathrm{M}$ caustic treated, Sk-3 for $2 \mathrm{M}$ and Sk-4 for $3 \mathrm{M}$ caustic treated. The reaction happened during nanoparticle formation is shown in Eq. 1. The digital image of treated and untreated fabric is exposed in Fig. 1 and the colour difference is shown in Table 2.

$2 \mathrm{Ag}^{+}+\mathrm{C}_{6} \mathrm{H}_{8} \mathrm{O}_{6} \rightarrow 2 \mathrm{Ag}^{0}+\mathrm{C}_{6} \mathrm{H}_{6} \mathrm{O}_{6}+2 \mathrm{H}^{+}$

\subsubsection{Dyeing}

Cotton fabric with silver nanoparticle is dyed by $2 \%$ direct dye in exhaust method at $60^{\circ} \mathrm{C}$ temperature on $55 \mathrm{~min}$ in a

Table 1 Specification of knit fabric

\begin{tabular}{llllll}
\hline $\begin{array}{l}\text { Fabric } \\
\text { structure }\end{array}$ & $\begin{array}{l}\text { Fabric } \\
\text { type }\end{array}$ & $\begin{array}{l}\text { Count } \\
(\mathrm{Ne})\end{array}$ & $\begin{array}{l}\text { Stitch } \\
\text { length } \\
(\mathrm{mm})\end{array}$ & $\begin{array}{l}\text { Weight } \\
\left(\mathrm{gm} / \mathrm{m}^{2}\right)\end{array}$ & $\begin{array}{l}\text { Thickness } \\
(\mathrm{cm})\end{array}$ \\
\hline $\begin{array}{c}\text { Single } \\
\text { jersey }\end{array}$ & Cotton & $24 / \mathrm{s}$ & 2.80 & 180 & 0.1 \\
\hline
\end{tabular}



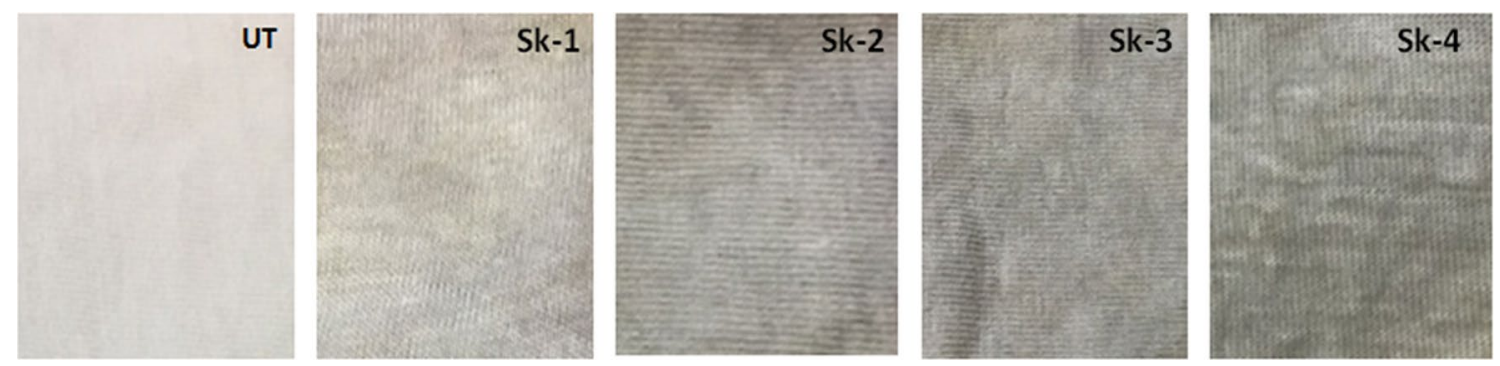

Fig. 1 Digital image of untreated (UT) and treated fabrics as samples of Sk-1, Sk-2, Sk-3 and Sk-4

Table 2 Colour differences of nano deposited fabric

\begin{tabular}{llrllr}
\hline Sample name & \multicolumn{1}{l}{$\mathrm{L}^{*}$} & \multicolumn{1}{l}{$\mathrm{a}^{*}$} & \multicolumn{1}{l}{$\mathrm{l}$} & \multicolumn{1}{l}{$\mathrm{W} / \mathrm{S}$} \\
\hline Untreated & $88.24 \pm 0.03$ & $-0.18 \pm 0.02$ & $0.22 \pm 0.01$ & 0.013 & 68.79 \\
Sk-1 & $83.31 \pm 0.02$ & $0.42 \pm 0.01$ & $2.13 \pm 0.22$ & 1.34 & -10.07 \\
Sk-2 & $60.21 \pm 0.04$ & $0.21 \pm 0.04$ & $5.17 \pm 0.31$ & 1.56 & -6.07 \\
Sk-3 & $52.00 \pm 0.01$ & $0.5 \pm 0.02$ & $4.16 \pm 0.24$ & 1.82 & -6.07 \\
Sk-4 & $47.11 \pm 0.02$ & $1.28 \pm 0.03$ & $1.38 \pm 0.32$ & 1.91 & -4.07 \\
\hline
\end{tabular}

sample dyeing machine at 1:10 liquor ratio. It is then rinsed and washed properly with distilled water.

\section{Analysis and measurements}

\subsection{Scanning electron microscopy (SEM)}

SEM is a type of electron microscope that produces images of a sample by scanning the surface with a focused beam of electrons. Here field emission electron microscopy (JSM600 , Tokyo, Japan) is used for this purpose. The fabric of nano $\mathrm{Ag}$ is well washed with distilled water before SEM test. The SEM image shows the morphology, size and distribution of silver nanoparticles on knitted fabric surface.

\subsection{Determination of silver content}

Silver content of cotton fabric with in situ deposited nano silver is measured by atomic absorption spectroscopy (AAS spectra 220), where $0.2 \mathrm{~g}$ of every silver decorated sample is immersed in $30 \mathrm{~mL}$ of $15 \mathrm{wt} \%$ of Nitric acid in separate pot. It is kept for $2 \mathrm{~h}$ at $80^{\circ} \mathrm{C}$ temperature then silver concentration is measured by flame atomic absorption spectroscopy [24]. The Eq. 2 is used to determine silver content as

Silver content $=\frac{C_{s}}{W_{d} /\left(1-\frac{M_{c}}{100}\right)} \times V$

where $C_{s}$ denote the silver concentration in extracted solution, $\mathrm{V}$ is the volume of extracted solution in Liter $(\mathrm{L})$ and
Wd is weight of dried cotton fabric and $M_{c}$ is the moisture content.

\subsection{X-ray diffraction (XRD)}

XRD Pattern of silver nanoparticles deposited cotton fabric is measured by X-Ray Defractometer (Phillips, Expert pro, Holland). This image can identify the crystal structure, shape and size of synthesized particles.

\subsection{Fourier Transform Infrared Spectroscopy (FTIR)}

FTIR is used to check the chemical changes and bonding interaction of cotton fabric with nano silver. Both of the untreated and treated cotton fabrics are characterized by FT-IR/NIR spectrophotometer (Model: Frontier, Perkin Elmer, USA). Scanning area is in the range of $4000-700 \mathrm{~cm}^{-1}$.

\subsection{Antimicrobial activity}

The antimicrobial property of the untreated and silver treated fabrics is evaluated by ASTM E2149-01. Antimicrobial activity is examined against Staphylococcus aureus (gram positive) and Escherichia coli (gram negative) bacteria. It is expressed in terms of reduction \% of the organism contact with the test specimen compared to the number of bacterial cells surviving after contact with the untreated sample as calculated by Eq. 3 .

Bacterial Reduction $\%=\frac{B-A}{B} \times 100$ 
where $A$ is the surviving cells $(\mathrm{CFU} / \mathrm{mL})$ for the flasks containing test samples (nano Ag deposited cotton) and B is that for the untreated sample (blank cotton) after $1 \mathrm{~h}$ contact time.

\subsection{Dyeing performances}

\subsubsection{Exhaustion (\%)}

The process of transfer of dyestuff from the dye bath on to the fiber or material is known as exhaustion. The ratio between the amount of dye taken up by the substrate and the amount of dye originally available is called exhaustion. The formula for calculation of exhaustion is shown by Eq. 4 , where $C_{o}=$ initial concentration of dye in dye bath and $\mathrm{C}_{\mathrm{s}}=$ concentration during the process

Exhaustion $\%=\frac{C_{0}-C_{s}}{C_{0}}$

\subsubsection{Colour strength}

Colour strength of silver nano deposited cotton fabric is measured by spectrophotometer (Data colour). The machine is characterized as follows: CIE LAB colour space, 10 degree observer with D65 illuminate $d / 2$ viewing geometry and measurement area of $2 \mathrm{~mm}$. Colour measurement parameters are lightness $\left(L^{*}\right)$ from black $(0)$ to white $(100),\left(a^{*}\right)$ is a red $(+) /$ green $(-)$ ratio, $\left(b^{*}\right)$ is yellow $(+) /$ blue $(-)$ ratio. Each data point is the average of two independent measurements. The colour strength of fabric is calculated by Kubelka-Munk theory [25] using the Eq. 5 .

$\mathrm{K} / \mathrm{S}=\left[\left\{(1-\mathrm{R})^{2} / 2 \mathrm{R}\right\}\right]$

where $\mathrm{R}$ is the reflectance, $\mathrm{K}$ is absorbance coefficient and $S$ is the scattering coefficient.

\subsubsection{Color fastness}

It is the resistance of colour of textiles to fade or bleed against different agencies such as light, wash, water, perspiration, rubbing, acid, alkali, hot pressing, bleaching etc. Colour fastness to wash, rubbing and light is measured by test method called ISO105CO4, ISO105X12 and ISO105B02, respectably.

\subsection{Mechanical properties (bursting strength)}

Bursting strength is a method of measuring fabric strength where the material is stressed in all directions at the same time. It is an alternative method to measure tensile strength but main way to evaluate the strength of knitted fabric. In this research bursting strength is measured by Truburst machine of James Heal, following the method of ISO 13938-2:1999.

\subsection{Wash durability}

The silver nanoparticles deposited fabric samples are subjected to 5,10 and 15 home laundering cycle by using the method: AATCC 61-2009.

\section{Results and discussion}

\subsection{SEM: surface morphology}

The morphological change of cotton fabric caused by in situ deposition of silver nanoparticles is examined by scanning electron microscopy. The SEM image is shown in the Fig. 2a-e, which represents the clear deposition of silver nanoparticles on treated fabric. It is similar to the image of Rafie et al. [26] where the silver nanoparticles are bio synthesized. It is also observed from Fig. 2 that due to high concentration of alkali the amount of nanoparticle deposition increases. That means the more concentration of $\mathrm{NaOH}$, the more deposition of silver nanoparticles [(d) and (e)]. Caustic concentration of $3 \mathrm{M}$ as given in Fig. 2e shows lot of agglomerated particles. The SEM images demonstrate the much deposition of silver nanoparticles on fabric surface due to the formation of Cell-O $\mathrm{ONa}^{-}$ through alkali which acts as an effective host for the silver ion and the size of particles are reduce to nano level by acid reduction.

\subsection{Energy dispersive spectroscopy (EDS)}

It is recorded to determine the elemental composition of chemical of treated and untreated samples.

It confirms the presence of silver nanoparticles on treated fabric. The graphical presentation of EDS analysis of nano deposited sample, Sk-4 is shown in Fig. 2f. The figure clearly shows that the silver deposited sample give the peaks on $3 \mathrm{keV}$ which attributes to the signal of silver formation. The mass percentage of silver nano particles is also obtained from EDS, which confirms more concentration of $\mathrm{NaOH}$ causes more amount of nano Ag growth. The obtained mass percentage is shown in Table 3.

\subsection{XRD analysis}

Crystalline size and structure of the silver nanoparticles are measured by XRD (X-Ray Diffraction Spectroscopy). Figure 3a-d shows the XRD image of all four treated sample. The characteristics picks of the image clearly indicate 

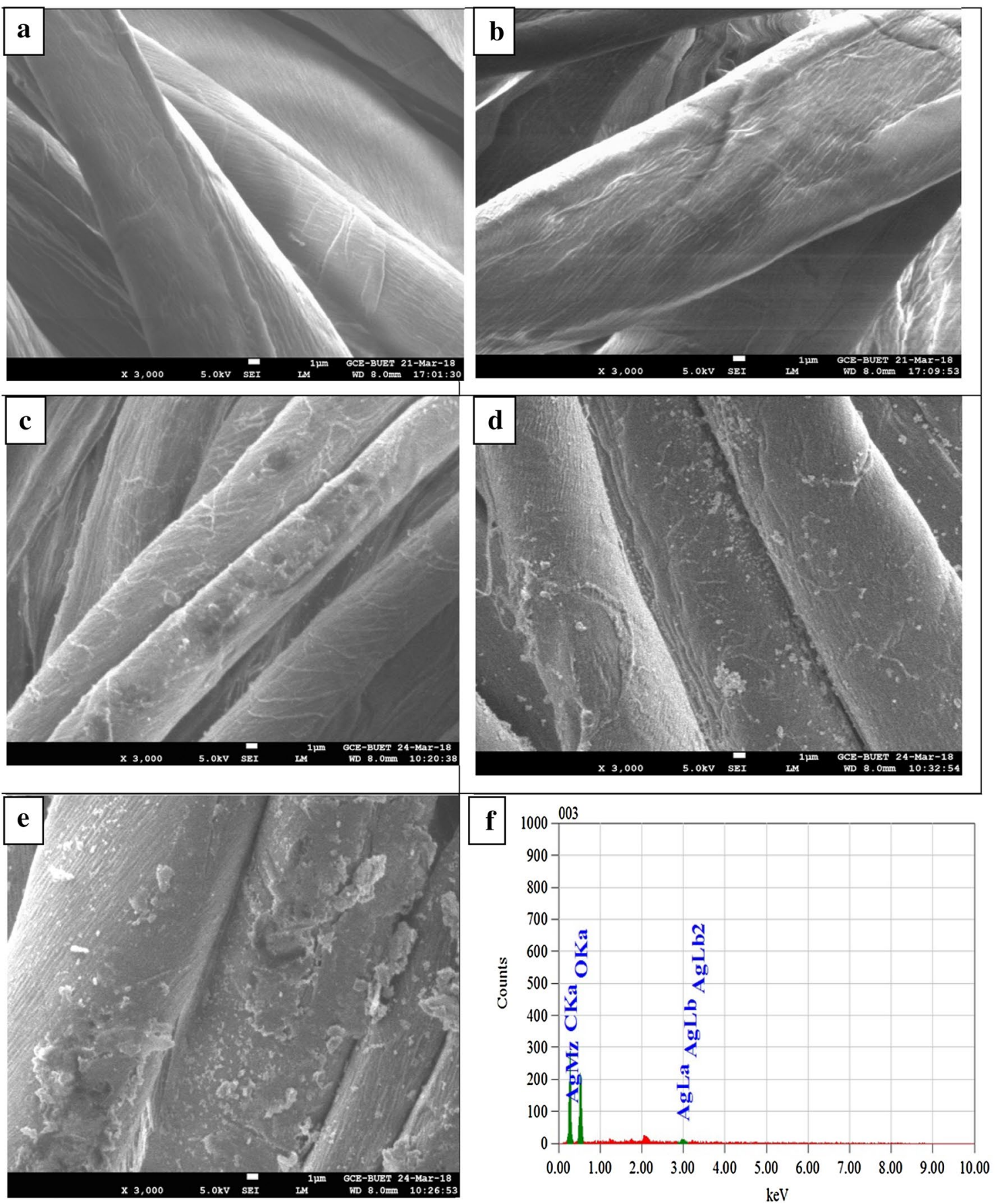

Fig. 2 SEM (scanning electron microscopy) image of a untreated fabric b Sk-1, c Sk-2, d Sk-3, and e Sk-4; f EDS image of Sk-4

Table 3 The chemical element of untreated and treated fabric in percentage of mass obtained by EDS

\begin{tabular}{llrrrr}
\hline \multirow{2}{*}{ lement } & \multicolumn{5}{l}{ Amount (\% of mass) } \\
\cline { 2 - 6 } & Untreated & Sk-1 & \multicolumn{1}{c}{ Sk-2 } & Sk-3 & Sk-4 \\
\hline C & 51.37 & 50.64 & 49.08 & 48.08 & 47.28 \\
O & 48.63 & 47.67 & 47.47 & 47.47 & 46.48 \\
Ag & 0 & 1.68 & 3.45 & 4.44 & 5.43 \\
\hline
\end{tabular}

the presence of silver nanoparticles on every treated fabric sample (Sk-1 to Sk-4). Similar picks of silver nanoparticles are obtained on synthesized of silver nanoparticle from leaf extract by Mahendran et al. [28] and Singh and Khanna on their in-situ synthesized nano Ag [27]. In Fig. 3 the distinct picks of $2 \theta$ exhibits at $38.22^{\circ}, 44.5^{\circ}, 64.82^{\circ}$, $78^{\circ}$ are assigned to corresponding reflection through the planes of (1 111$),\left(\begin{array}{lll}2 & 0 & 0\end{array}\right),\left(\begin{array}{lll}2 & 2 & 0\end{array}\right)$, and ( $\left.\begin{array}{lll}3 & 1 & 1\end{array}\right)$ respectively, 


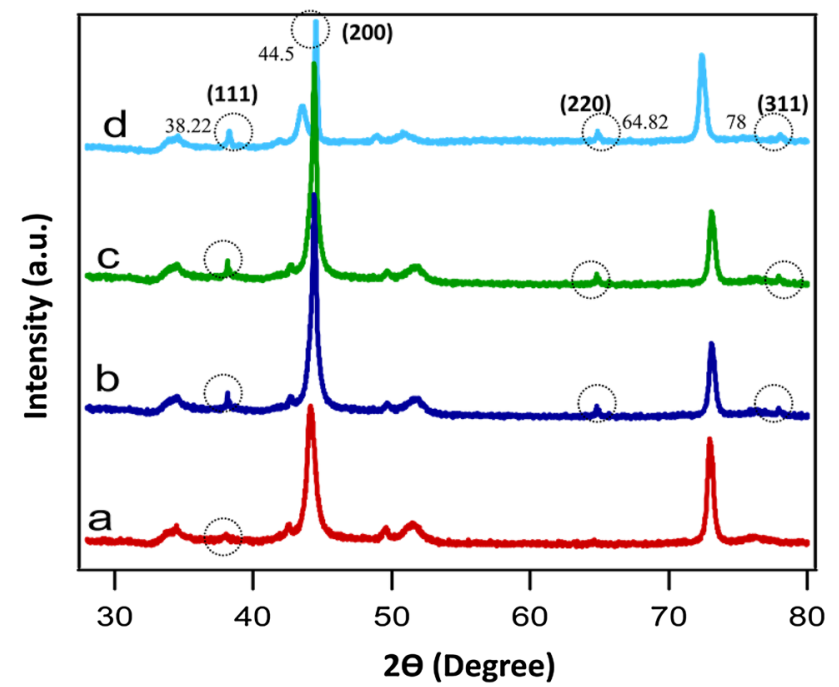

Fig. 3 XRD (X-ray diffraction spectroscopy) of a silver deposited and without alkali pretreated sample Sk-1, b-d silver deposited with alkali pretreated on different concentration Sk-2, Sk-3 and Sk $-4$

indicates the silver nanoparticles are fcc (Face centered cubic) and crystalline in nature. The peaks are almost same for all treated sample pointed by circle on figure. The other peaks are corresponding peaks of cellulosic structure. Only for Sk-1, the peak at $65^{\circ}$ and $78^{\circ}$ is absent. The mean size of silver nano particles is calculated using the Debye-Scherrer's equation [29] as Particle Size $=(0.9 \times \lambda) /(\mathrm{d} \cos \theta)$, where $\theta=2 \theta / 2, d=$ the full width at half maximum intensity of the peak, $\lambda$ is the wavelength of $X$-ray source $\left(1.54056 \mathrm{~A}^{\circ}\right)$. From this equation it is found that the calculated average size of silver nano particle is around $14.1 \mathrm{~nm}$.

\subsection{Silver content}

The results on Table 4 clearly indicate the deposition of silver on treated fabric. The sample Sk-1 shows lowest amount of silver content than others, whereas, sample Sk-4 gives highest amount of silver content. Table 4 indicates an increasing rate of silver deposition from Sk-2 to Sk-4 that means the more of caustic concentration, the more of nano silver content. So the result proves that

Table 4 Silver content of untreated and treated fabric

\begin{tabular}{ll}
\hline Sample & Silver conton $(\mathrm{g} / \mathrm{Kg})$ \\
\hline Untreated & 0 \\
Sk-1 & $0.11 \pm 4.25$ \\
Sk-2 & $2.60 \pm 5.02$ \\
Sk-3 & $5.40 \pm 3.02$ \\
Sk-4 & $10.00 \pm 5.03$ \\
\hline
\end{tabular}

SN Applied Sciences the content of nano silver deposition depends on alkali concentration.

\subsection{FTIR spectroscopy}

The fourier transform spectrum of treated and untreated samples are represented in Fig. 4. The trends of three different curves in the figure are quite similar. It generally shows the characteristic peaks for the main functional groups of cellulosic structure of cotton fabrics. It can be pointed out that the cellulosic structure includes the peaks in $3340-3353 \mathrm{~cm}^{-1}, 2913-2997 \mathrm{~cm}^{-1}, 1441-1467 \mathrm{~cm}^{-1}$ and $1033-1114 \mathrm{~cm}^{-1}$, which attributes to $3347 \mathrm{~cm}^{-1}(\mathrm{O}-\mathrm{H}$, stretching), $2919 \mathrm{~cm}^{-1}\left(\mathrm{C}-\mathrm{H}\right.$, stretching), $1163 \mathrm{~cm}^{-1}(\mathrm{C}-\mathrm{O}$, stretching) and $1034 \mathrm{~cm}^{-1}$ (C-O-C) according to IR table. It is clearly observed that there is no significant change occurred on cotton due to caustic $(\mathrm{NaOH})$ as well as silver treatment, which is similar to the work of Li Shuhui et al. [30]. Therefore, it is stated that treatment of cotton fabric with nano silver does not affect on the molecular structure of fabrics [31], and this assures that there is no chemical interaction between cellulosic chains and silver nanoparticle. Only the sample Sk-4 (3M caustic soda) in Fig. 4 shows that the intensity of some peaks is reduces very slightly. It indicates that $\mathrm{NaOH}$ treatment decreases the intensity of hydroxyl group (-OH) [32]. So the contact between fibers and metallic silver nanoparticles happens only by the physical adsorption of silver nanoparticles on fabric surface.

\subsection{Antimicrobial effect}

The antimicrobial activity of treated and untreated cotton fabrics are presented on Table 5. Treated sample shows excellent bacterial reduction against both bacteria of gram

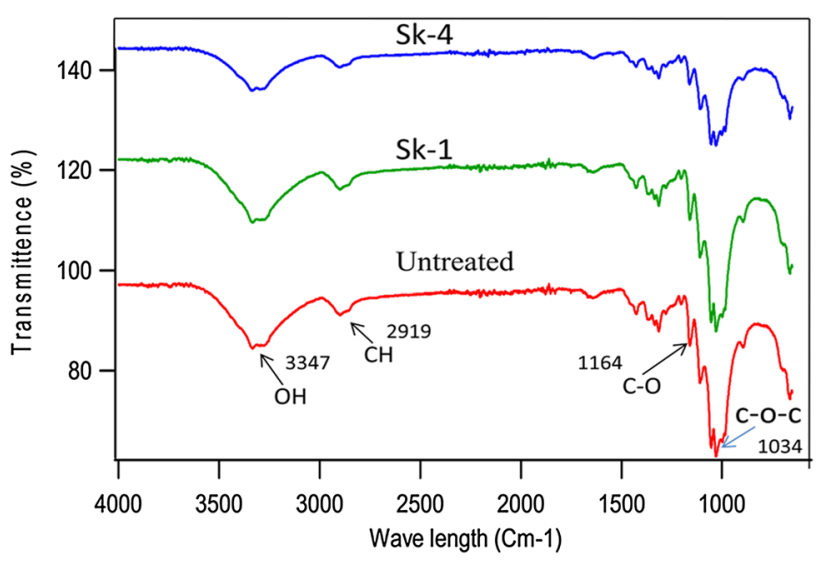

Fig. 4 FTIR spectrum of untreated fabric, nano Ag deposited fabric without $\mathrm{NaOH}$ pretreatment (Sk-1), and nano Ag deposited fabric pretreated with $3 \mathrm{M}$ of $\mathrm{NaOH}(\mathrm{Sk}-4)$ 
Table 5 Bacterial reduction percentage of treated fabric

\begin{tabular}{lll}
\hline Sample & $\begin{array}{l}\text { Bacterial reduction ( } \mathrm{R} \%) \\
\text { for S. aureus (gram posi- } \\
\text { tive) }\end{array}$ & $\begin{array}{l}\text { Bacterial reduction (R\%) } \\
\text { for E. coli (gram negative) }\end{array}$ \\
\hline
\end{tabular}

\section{Sk-1}

$\begin{array}{lll}\text { Unwashed } & 33 & 26 \\ 5 \text { wash } & 20 & 20 \\ 10 \text { wash } & 20 & 20 \\ 15 \text { wash } & 20 & 13 \\ \text { Sk-2 } & & \end{array}$

Unwashed $76 \quad 66$

5 wash $\quad 66 \quad 57$

10 wash 61

15 wash $55 \quad 54$

Sk-3

Unwashed 91

5 wash $\quad 62 \quad 66$

10 wash $61 \quad 60$

15 wash $54 \quad 60$

Sk-4

$\begin{array}{lll}\text { Unwashed } & 95 & 92 \\ 5 \text { wash } & 76 & 76 \\ 10 \text { wash } & 66 & 66 \\ 15 \text { wash } & 66 & 46\end{array}$

positive and gram negative. It is also observed that there is a relation between the amount of nanoparticle and the $\%$ of bacterial reduction. Result indicates, presence of more silver nanoparticle causes higher antimicrobial activity because $3 \mathrm{M}$ caustic treated sample shows highest bacterial reduction (R\%) whereas, the sample without caustic shows comparatively lower R\% (Table 5). The image of antimicrobial rate is presented on Fig. 5 that proof the bacterial reduction is higher on treated fabric for both two bacteria. All results of antimicrobial test evident that the Ag nano deposited fabric is more effective on gram positive bacteria than gram negative. The treated sample is capable of reducing bacteria up to $95 \%$ for sample Sk-4, even after 15 home laundering. Washing durability is also good as the sample retains $46 \%$ bacterial reduction after washing. Additionally, in a recent work, Azam et al. investigated the cytotoxicity effects of a cellulose paper sample decorated with Ag nanoparticles. The investigation confirmed that this kind of Ag modified surfaces is not toxic to plant and animal tissues [33].

\subsection{Bursting strength}

The result of bursting strength test is plotted in the Fig. 6 . From the figure it is observed that the treated sample shows lower bursting strength than untreated fabric. The sample Sk-4 with $3 \mathrm{M}$ caustic soda is showing lowest strength which is $230.73 \mathrm{kPa}$ whereas, untreated sample gives $286.92 \mathrm{kPa}$. However the loss of bursting strength is not linear with the concentration of caustic soda. For sample, Sk-4 loses approximately $13 \%$ strength, whereas sample Sk-2 having $1 \mathrm{M}$ caustic soda loses only $3 \%$. The reason is that more amount of caustic soda causes higher celluloseate formation which is responsible for strength fall.

\subsection{Colour performance}

The nano treated and dyed cotton fabric shows better result in dye exhaustion (\%), colour strength, and fastness property. The colour strength is higher in all four

Bursting Strength $(\mathrm{kPa})$

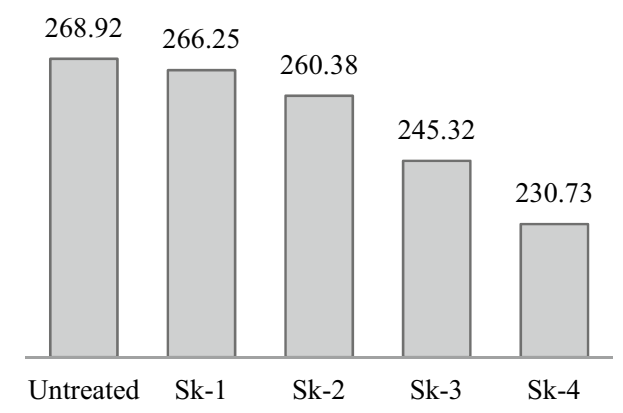

Fig. 6 Bursting strength of untreated and treated fabric
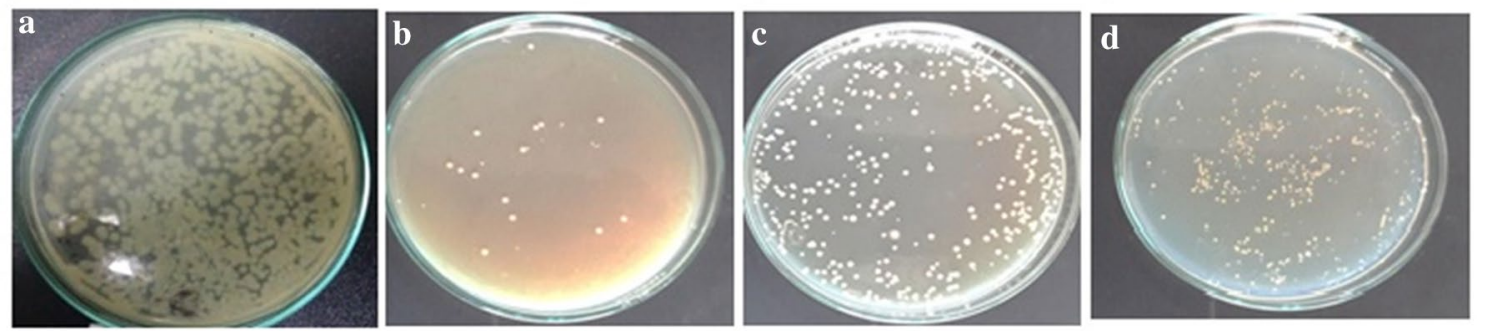

Fig. 5 Reduction rate of bacteria by a untreated fabric against S. aureus b silver deposited fabric Sk-4 against S. aureus c untreated fabric against $E$. coli, d silver deposited fabric Sk-4 against $E$. coli 
Table 6 Colour performance of untreated and treated Fabric

\begin{tabular}{llllll}
\hline Sample & Exhaustion \% & $\begin{array}{l}\text { Colour } \\
\text { strength } \\
(\mathrm{k} / \mathrm{s})\end{array}$ & \multicolumn{2}{l}{ Colour fastness } \\
\cline { 4 - 6 } & & & $\begin{array}{l}\text { Wash } \\
\text { (shade } \\
\text { change) }\end{array}$ & Rubbing Light \\
& & & 2 & 2 & 3 \\
\hline Untreated & 65 & 11.35 & 2 & 2 & $3-4$ \\
Sk-1 & 65 & 11.5 & 2 & 2 & $3-4$ \\
Sk-2 & 63 & 12.12 & $2-3$ & $2-3$ & 4 \\
Sk-3 & 68 & 13.20 & $2-3$ & 3 & 4 \\
Sk-4 & 70 & 13.34 & $2-3$ & &
\end{tabular}

treated fabric, where sample Sk-4 shows best depth of colour compared with untreated fabric. The obtained results are arranged in Table 6 . It is well defined that silver is a metal which have inheriting antimicrobial property and it acts as a mordent to grab more dyestuff on fabric. As a result better colour performance is obtained on direct dyed cotton fabric due to nano Ag deposition. Moreover the metal nano silver increases the dye affinity of cotton fabric. The fastness properties are also increases by nano Ag deposition.

\section{Conclusions}

An easy and improved technique is used to synthesis silver nanoparticles on fabric surface to develop finished fabric with high antimicrobial activity. The SEM and EDS report proves well deposition of nano Ag on fabric. The size of the particle is obtained by XRD pattern analysis as $14.1 \mathrm{~nm}$. The content of silver nanoparticles increases with the increase of caustic soda concentration. However, the increment of nano particle deposition is not linear with the increase of caustic soda concentration. FTIR spectrum shows that there is no bonding phenomenon occurred on cotton fabric due to nano Ag formation. The bacterial reduction is found excellent and is $95 \%$ for $S$. aureus and $92 \%$ for E. coli. The action of treated sample against gram positive bacteria is quite higher than that of gram negative bacteria. The study reflects that antimicrobial activity depends on the amount of the deposition of Ag nanoparticles. Further important, the nano deposited fabric shows enhancement of colour strength, exhaustion and fastness property of direct dyed cotton, which causes quantitative reduction of dyestuff for dyeing and hence the dye house effluent resulting in reduction of environmental pollution.

\section{Abbreviations}

1. SEM-Scanning Electron Microscopy

2. EDS-Energy Dispersive Spectroscopy

3. XRD-X-Ray Dispersive Spectroscopy

4. FTIR-Fourier Transform Infrared Spectroscopy

5. R\%-Reduction percentage of bacteria

6. WI-Whiteness Index

7. $\mathrm{K} / \mathrm{S}$-Color Strength

8. Color measurement parameters are lightness $\left(L^{*}\right)$ from black (0) to white $(100), a^{*}$ is a red $(+) / g r e e n(-)$ ratio, b*is yellow $(+) /$ blue

Acknowledgements The authors would like to acknowledge the amenity provided by Bangladesh University of Engineering and Technology (BUET) for silver nano particle synthesis and characterization such as SEM, EDS and XRD. We also like to acknowledge Prof. Dr. Suvamoy Datta for the facility of antimicrobial test on the department of microbiology of University of Primeasia. The FTIR analysis is supported by Fibre and Polymer division of BCSIR (Bangladesh Council of Scientific and Industrial Research). Some physical test opportunity is given by Bangladesh University of Textiles (BUTEX).

Authors' contribution Author IST defined the research plane under the supervision of Prof. Dr. MA. Dr SA gives some ideas about AAS (atomic absorption spectroscopy) test and guided about in situ synthesis process.

Funding There is no funding of this work. It is a part of Ph.D. research of Bangladesh University of Engineering and Technology (BUET). All cost of experiment will be provided by university after completion of the degree.

\section{Compliance with ethical standards}

Conflict of interest The authors declare that they have no conflict of interest.

Availability of data and materials The data based used for analysis can be provided for reasonable request by corresponding author.

\section{References}

1. Simoncic M, Tomsic B (2010) Structures of novel antimicrobial agents for textiles-a review. Text Res J 80(16):1-17

2. Wang L, Chen H, Shao L (2017) The antimicrobial activity of nanoparticles: present situation and prospects for the future. Int J Nano Med 12:1227-1249

3. Joshi M, Bhattacharyya A (2011) Nanotechnology: a new route to high performance and functional textiles. Text Prog 43(3):155-233

4. Yadav A, Prasad V, Kathe AA (2006) Functional finishing in cotton fabrics using zinc oxide nanoparticles. Bull Mater Sci 29(6):641-645

5. Parthasarathi V, Thilagavathi G (2009) Synthesis and characterization of titanium dioxide nano-particles and their applications to textiles for microbe resistance. J Text Appar Technol Manag 6(2):468-476 
6. Joshi M (2005) Nanotechnology: opportunities in textiles. Indian J Fiber Text Res 30:477-479

7. Zhang F, Xiaolan W, Chen Y, Lin H (2009) Application of silver nanoparticles to cotton fabric as an antibacterial textile finish. Fibers Polym 10(4):496-501

8. Gokarneshan IN, Gopalakrishnan PP, Jeyanthi B (2012) Influence of nanofinishes on the antimicrobial properties of fabrics. Int Sch Res Netw ISRN Nanomater 8:1-8

9. Raza ZA, Rehman A, Usman FAAA (2016) Development and antibacterial performance of silver nanoparticles incorporated polydopamine-polyester-knitted fabric. Bull Mater Sci 39(2):391-396

10. Kilinca M, Canbolata S, Merdana N, Dayioglua H, Akinb F (2015) Investigation of the color, fastness and antimicrobial properties of wool fabrics dyed with the natural dye extracted from the cone of Chamaecyparis lawsoniana. Proc Soc Behav Sci 195(3):2152-2159

11. Gokarneshan N, Velumani K (2017) Application of nano silver particles on textile materials for improvement of antibacterial finishes. Glob J Nano Med 2(3):1-4

12. Morones JR, Elechiguerra JL, Camacho A, Holt K, Kouri JB, Ramírez JT, Yacaman MJ (2005) The bactericidal effect of silver nanoparticles. Nanotechnology 16(10):2346-2353

13. Vigneshwaran N, Kathe AA, Varadarajan PV, Nachane RP, Balasubramanya RH (2007) Functional finishing of cotton fabrics using silver nanoparticles. J Nanosci Nanotechnol 7(6):1893-1897

14. Falletta E, Bonini M, Fratini E (2008) Clusters of poly (acrylates) and silver nanoparticles: structure and applications for antimicrobial fabrics. J Phys Chem C 112(31):11758-11766

15. Yeo MK, Kang M (2008) Effects of nanometer sized silver materials on biological toxicity during zebrafish embryogenesi. Bull Korean Chem Soc 29:1179-1184

16. Capek I (2004) Preparation of metal nanoparticles in water-in oil (w/o) microemulsions. Adv Colloid Interface 110(1-2):49-74

17. Sharma VK, Yngard RA, Lin Y (2009) Silver nanoparticles: green synthesis and their antimicrobial activities. Adv Colloid Interface 45:83-96

18. Son WK, Youk JH, Park WH (2006) Antimicrobial cellulose acetate nanofibers containing silver nanoparticles. Carbohydr Polym 65:430-434

19. Vimala K, Sivudu KS, Mohan YM (2009) Controlled silver nanoparticles synthesis in semi-hydrogel networks of poly (acrylamide) and carbohydrates: a rational methodology for antibacterial application. Carbohydr Polym 75:463-471

20. Sanchez LR, Blanco MC, Quintela MAL (2000) Electrochemical synthesis of silver nanoparticles. J Phys Chem B 104:9683-9688

21. Bacciarelli-Ulacha A et al (2014) A new method of finishing of cotton fabric by in situ synthesis of silver nanoparticles. Ind Eng Chem Res 53:4147-4155

22. Allahyarzadeh V, Montazer M, Nejad NH, Samad N (2013) In situ synthesis of nano silver on polyester using $\mathrm{NaOH} /$ nano $\mathrm{TiO}_{2}$. Appl Polym Sci 129:892-900

23. Shaheen TI, El Aty AAA (2018) In-situ green myco-synthesis of silver nanoparticles on to cotton fabrics for broad spectrum antimicrobial activity. Int J Biol Macromol 118(B):2121-2130

24. Emam HE, Zahran MK (2015) $\mathrm{Ag}^{\circ}$ nanoparticles coating on cotton fabric: synthesis characterization, colour data and antimicrobial action. Int J Biol Macromol 75:106-114

25. Fairchild MD (1997) Color appearance models. Addision Westley Longman Inc., Boston

26. El Rafie M, Shaheen T, Mohamed AA, Hebeish A (2012) Biosynthesis and applications of silver nanoparticles onto cotton fabrics. Carbohydr Polym 90(2):915-920

27. Singh N, Khanna PK (2007) In situ synthesis of silver nanoparticles in polymethylmethacrylate. Mat Chem Phys 104:367-372

28. Vanaja M, Annadurai G (2013) Coleus aromaticus leaf extract mediated synthesis of silver nanoparticles and its bactericidal activity. Appl Nanosci 3:217-223

29. Waseda Y, Matsubara E, Shinoda K (2011) X-ray diffraction crystallography. Springer, New York

30. Li S, Zhu T, Huang J, Guo Q, Chen G, La Y (2017) Durable antibacterial and UV-protective $\mathrm{Ag} / \mathrm{TiO}_{2}$ fabrics for sustainable biomedical application. Int J Nanomed 12:2593-2606

31. Aladpoosh R, Montazer M, Samadi N (2014) In situ green synthesis of silver nanoparticles on cotton fabric using Seidlitzia rosmarinus ashes. Cellulose 21:3755-3766

32. Asghar U, Irfan M, Iram M, Huma Z, Nelofer R, Nadeem M, Syed $Q$ (2015) Effect of alkaline pretreatment on delignification of wheat straw. Nat Prod Res 29(2):125-131

33. Islam MS, Akter N, Rahman MM, Islam T, Zeng H, Azam MS (2018) Mussel-inspired immobilization of silver nanoparticles toward antimicrobial cellulose paper. ACS Sustain Chem Eng 6(7):9178-9188 